\title{
The Analysis of Chinese Enterprises' Innovation System under Environment Perspective
}

\author{
Xiang-Xiang WANG ${ }^{1, a, *}$ \\ ${ }^{1}$ School of Management, Harbin University of Science and Technology, P. R. China, 150080 \\ wangxiangxiang0309@126.com \\ ${ }^{*}$ Corresponding author
}

Keywords: Innovation, Innovation system, Environment.

\begin{abstract}
China as an important part of the global system, it will inevitably face the impact of global climate change on various aspects of the ecosystem, industry, and society. Low level of technology and resource endowments determines the characteristics of Chinese enterprises in the low-end position of global value chain. Changing Chinese enterprises with high energy consumption, high pollution and high emission mode of development, it is great significance to achieve ecological, economic, social balance globalization of Chinese enterprises for sustainable development of. At the same time, whether the point of from domestic development, or from the point of view of international, the improvement of innovation of Chinese enterprises has important practical significance competition for economic and social development.
\end{abstract}

\section{Introduction}

China's economy maintained a rapid growth in the industrial economy era, but also brought a wide range of resources exploitation, wanton destruction of the environment, ecology suffered a catastrophe can not repair itself [1]. Environmental and economic development-friendly economic patterns, sustainable economic form are wise choices to make, which will also contribute to better survival and development for mankind. Long-term developments in developed countries drives from continuous innovation, for the vital national interest consideration, the developed countries have the technical monopoly and would not easily transfer the high technology to China. Similarly, multinational corporations maintain their dominance for strategic needs, will control the technology, design and other critical resources and core technologies, not easily transfer core technology. Therefore, if enterprises rely solely on the developed countries technology, it is difficult to catch up their technology gap. Although China may be more mature by the introduction of foreign technology to continuously improve the level of local industries, but disadvantages problems never completely be solved. Latecomer disadvantage problem cannot be solved fundamentally by the way of imitation, digestion and absorption. Only through long-term continuous innovation, technological breakthroughs have finally achieved economic catch-up, overcome latecomer disadvantage, constantly moved to the forefront of high-end segments. And to achieve this sustainable development is the fundamental way to improve the capability of innovation.

\section{Innovation environment}

\section{Natural environment}

The natural environment is the sum of the various natural factors, such as air, water, plants, animals, soil, rocks and minerals and so on. These are the material basis for human survival. Human beings are products of nature, but human activities are counterproductive to the natural environment.

\section{Policy and legal environment}

Policy and legal environment is the legal system of a series of principles, policies, laws and regulations, which promoting economic and technological development of countries and 
regions .Among them, the government policy is external force for the enterprises innovation, the main role of government policy is to coordinate national public financial resources, efficient allocation of resources for research and development, to encourage enterprises innovation activities ,to safeguard the legitimate interests of the main innovation. The role of policy and law on the ability of innovation is enormous, sometimes radically. Not only does it regulate other environmental factors, but also affects the operation mechanism of innovation capability system. A good policy on the capability of innovation system has a positive role in promoting, on the contrary, it will have them back.

\section{Market environment}

Market environment including market demand, market competition. The ultimate aim of enterprises innovation is admitted by the market. Therefore, the success of innovation, and analysis of the market situation and future development, and enterprises understand their users' needs are closely linked. The biggest problem currently affecting the power of innovation is the lack of fair market competition environment. China currently exist bad order, insufficient competition, inadequate information and unfair competition and other issues, these result in innovation activities hampered and not enthusiastic. For businesses, regardless of how its existing competitive advantages obviously, we can not guarantee its existing dominant position forever, there will be other companies may surpass. Therefore, the pressure of market competition is also a driving force for innovation and drive enterprises to improve capacity.

\section{Technical factors}

Technical factors refer to the degree of scientific technological development, in particular the level of development of information and transportation technologies. Technical environment is communication environment of various technical aspects of the innovation system. To achieve technology cooperation, technology transfer, technology development activities, we must rely on good technical communication environment, only the flow of information technology environment, companies can make good use of technology innovation resources and complete innovation activities in a short period of time.

\section{Socio-economic and cultural environment}

Socio-economic and cultural environment mainly refers to foster or restrain innovation and its effective role socio-economic and cultural factors, including the objective economic environment and socio-cultural environment.

\section{The development trend of innovation}

\section{Intensify the introduction of technology and innovation}

Strengthening international cooperation of technology to improve the international competitiveness of China's enterprises technology. China should adjust the focus of the technology introduction, shift from hardware-based to technology licensing, consulting, technology services and other track.

\section{Improve the capability of innovation}

Current China's scientific and technological innovation capability have a big gap with the world's leading level. China's enterprises should reduce the cost of technological innovation stage through the purchase of foreign technical data, equipment, and promote domestic technology to accelerate growth. When domestic technology with the developed countries is small gap, it should be to get high returns through innovation. 


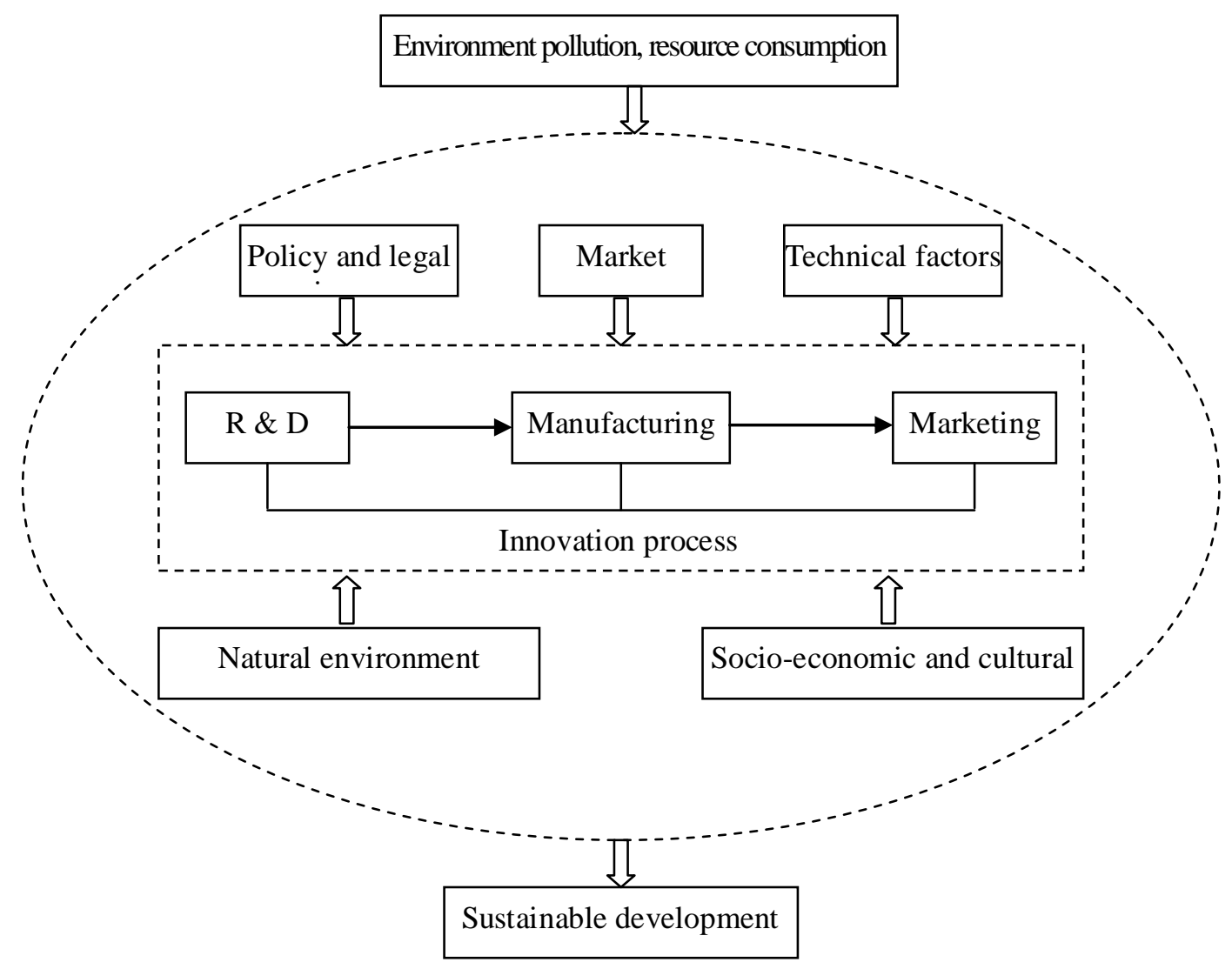

Fig.1 Chinese enterprises' innovation system under environmental perspective

\section{Based environmental perspective, enterprise innovation has the following characteristics}

\section{Subjective initiative}

Business innovation reflects the enterprise through its own efforts and joint research, to explore technology breakthrough, to achieve the desired goal. The whole process of business innovation requires the people's initiative requirements. Encouraging and mobilizing innovation consciousness of the innovation process, to enhance leading role of innovation capability.

\section{Environmental benefit}

In global warming and resource and environmental constraints background, China's enterprises should actively develop environmental technologies, which has basic characteristics of low power consumption, low emissions and high performance, high efficiency, energy saving, find new energy and efficiently make use of energy, change conventional energy patterns. These will play a positive role in promoting the environment and the harmonious development of society. Based environmental perspective, business innovation has environmental usefulness.

\section{Summary}

The formation and development of innovative systems research methods, closely related to the deepening of neo-Schumpeterian innovation theory. With in-depth technical innovation research conducted, scholars have come to realize: technological innovation is not a simple, linear process, but one with a complex feedback mechanism, and a complex process of various elements interaction, such as in science, technology, learning, production, policy, requirements, etc. formation of. Innovation process is affected by many factors, companies can not innovate itself. Lundvall (1992) thought that innovation system is a collection of various elements and their mutual relations [2]. Carlsson etc (2002) highlighted the status of technical knowledge in the innovation system, they thought innovation system is the collection of technical knowledge creation, 
diffusion and use, which contains all the elements and relationships between elements, as well as the characteristics and attributes of the elements [3].

\section{References}

[1] Foster. Ecological Crisis and Capitalism., Shanghai Translation Publishing House, 2006, pp.75-61.

[2] Lundvall B A. National Systems of Innovation Towards a Theory of Innovation and Interactive Learning., London Pinter Publishers, 1992.

[3] Bo Carlsson SJ, Magnus Holm N, Annika Rickne Innovation systems:.. Analytical and methodological issues, Research Policy 2002, pp. 233-245. 